\title{
Onomatopoeia and Cat Vocalisations
}

\author{
Aliaa Aloufi ${ }^{1}$ \\ ${ }^{1}$ Community College, Taibah University, Medina, Saudi Arabia \\ Correspondence: Aliaa Aloufi, Community College, Taibah University, Medina, Saudi Arabia. E-mail: \\ amsaufe@taibahu.edu.sa
}

Received: June 6, $2021 \quad$ Accepted: July 16, $2021 \quad$ Online Published: July 19, 2021
doi:10.5539/ijel.v11n5p14

\begin{abstract}
Onomatopoeia - the imitation of natural sounds - is a common phenomenon in human language, though imitations of the same sounds might appear different cross-linguistically. It is true that onomatopoeia is not like ordinary language, but how does it differ from natural vocalisation? While the distinction between onomatopoeia and ordinary language has received ample treatment, its difference from natural sounds have so far received less attention from linguistics. This study aims to investigate the phonetic differences between onomatopoeic cat sounds in ten languages and natural cat vocalisations. The findings show some segmental and phonotactical distinctions due to the direct representation of these words regarding their meanings, which clearly indicates that this phenomenon in world languages is not arbitrary and offers strong evidence of iconicity. While arbitrariness is the norm in human language and has an essential impact on language development, there are clearly some nonarbitrary aspects of human language, and onomatopoeia is notable among them.
\end{abstract}

Keywords: onomatopoeia, sound, vocalisations, arbitrariness, iconicity

\section{Introduction}

Onomatopoeia, with its odd spelling, refers to the "process of forming words whose phonetic form is perceived as imitating a sound, or sound associated with something, that they denote" (Matthews, 1997, p. 276). Its Greek root indicates that onomatopoeia is indeed the making (poiein) of a name or word (onoma) from natural sounds (Chalker \& Weiner, 1998). Consider how the sound made by a bee resembles the word buzz, and how this close resemblance between onomatopoeia and a natural sound poses a significant challenge to de Saussure's notion of the arbitrariness of language (Saussure, 1959). These are imitative words, or at least part of natural sounds (Saussure, 1959). Cross-linguistically, onomatopoeia exists in all the languages of the world, and some scholars, actually, consider onomatopoeic words to have been the earliest words spoken by humans during the development of human language, due to the fact that direct imitation allows the listener to straightforwardly recognise the meaning, hence it very clearly to describe animals such as a rooster with cock-a-doodle-do, which formed the bulk of the conversations between primordial humans (Yaqubi, Tahir, \& Amini, 2018). Therefore, this specific linguistic phenomenon is the focus of this study. The aim is to investigate cross-linguistic onomatopoeia of cat sounds in relation to cats' natural vocalisations. To achieve this aim, three research questions have been taken into consideration:

- How do the onomatopoeic words for cat sounds and cat vocalisations differ phonetically?

- How are onomatopoeia and cat vocalisation related?

- What is the impact of this relationship on the notion of arbitrariness in language?

The next section provides a basic theoretical background with regard to onomatopoeia and animal vocalisation, with a specific focus on cat vocalisation, after which there is a section demonstrating in detail the cross-linguistic onomatopoeic word and cat vocalisation dataset used in this research and highlighting the phonetic differences with a thorough analysis. The fourth section presents the study's discussion, while the conclusion, presented in the final section, provides a summary of the study and its findings.

\section{Theoretical Background}

Theory on the arbitrariness of language begins in the 1900s, with the claim made by Ferdinand de Saussure that all human languages are in fact arbitrary (Saussure, 1959). World languages are based on a process of naming. More precisely, things are linked to a particular name or word (Dofs, 2008). Concerning this process, two 
elements are involved, the signifier (a sound image) and the signified (a concept), resulting in a linguistic sign that is normally accepted by the speakers of the same language as contained in ordinary language (Dofs, 2008). Indeed, the diversity of words representing the same things in different languages signifies that the association between the signifier and the signified is indeed arbitrary (Dofs, 2008). Variety of meaning might be possible, as one signified can have several signifiers, and vice versa, leading to the notion of ambiguity in language (Driscoll et al., 2009). Arbitrariness made it possible for humans to develop more complex languages than animals, as it is easier to learn the sound-pairs of a given language that can be combined in several ways, than to develop an inherent system for communication in numerous diverse contexts (Klages, 2001).

Apparently, therefore, arbitrariness is the norm in human language, to the extent that the basic connection between the form and meaning is concerned (Valli \& Lucas, 2000). However, there are many nonarbitrary aspects to language. Non-arbitrariness can be found in other domains of language, the most notable and obvious being the onomatopoeic words, which are words imitative of "natural sounds or have meanings that are associated with such sounds of nature" (Valli \& Lucas, 2000, p. 276). Yet, in the case of such onomatopoeic words, a debate regarding arbitrariness is to be found. While "the form is largely determined by the meaning, the form is not an exact copy of the natural sound" (Valli \& Lucas, 2000, p. 277). For instance, English speakers have just arbitrary conventionalised cock-a-doodle-doo as the sound of roosters, even though do not actually say in that form. Furthermore, when different languages imitate the same sound, they have to make use of their own linguistic resources (Dofs, 2008). Different languages admit different sound combinations, so even the same natural sound may end up with a different form cross-linguistically, even though each form is somewhat imitative (Valli \& Lucas, 2000). For instance, a rooster sound in Chinese Mandarin is kukuku, even though rooster vocalisation is apparently the same in China and America.

As it is widely recognised that human language begins through human mimicry of naturally occurring sounds or movements, Peirce indicates that human language is iconic from the beginning (Peirce, 1867). Miller indicates that humans tend to connect certain sounds to certain actions and objects, which is somewhat related to modern theories of sound symbolism, but Miller claims that the instinct to connect sound to semantic fields disappeared as a result of language development (Abelin, 1999, p. 18). Some languages might be considered more iconic than others, because the use of onomatopoeia is controlled by the phonemes in the language (Dofs, 2008). As a result of linguistic restriction, a word such as 'crash' would not be possible in Japanese, because Japanese syllables cannot begin with a sequence like $\mathrm{kr}$ or end with a consonant like sh, and so on (Gasser, 2006). Iconic words, such as 'bow-wow', which is an imitation of a dog's bark, changed form and the meaning broadened, and finally 'bow-wow' became the representation for a dog (Corballis, 1999). The natural resemblance between a sign, and the concept or object in the real world which it refers to, can be classified as iconicity (Dofs, 2008). Iconicity is likeness to a concept — which includes our own impressions and ideas about something — corresponding to an object in our own perception of the world, and we all perceive the world in different ways (Dofs, 2008).

The cat, which is the focus of this study, is a very common pet around the world, with millions of individual cats having lived with humans over more than 10,000 years (Turner \& Bateson, 2000; Moelk, 1944). Cat vocalisations were first clarified by Moelk (1944), revealing the phonetic characteristics of domestic cats, followed by several pieces of research focusing on the acoustic characteristics of cat vocalisations (McKinley, 1982; Nicastro, 2004; Schötz \& Eklund, 2011; Schötz, 2012, 2013, 2015). Building on this, a phonetic typology phonetic of cat vocalisations, along with their phonetic descriptions, were identified (Schötz, Weijer, \& Eklund, 2017). Table 1 shows a classification of the most common cat vocalisation types and subtypes. Among the various cat vocalisations, this study will be largely based on the Meow types as will be discussed further, in detail, in the Discussion section.

Table 1. Classification of cat vocalisations (Schötz, Weijer, \& Eklund, 2017, p. 5)

\begin{tabular}{ll}
\hline Vocalisation Type & Subtypes \\
\hline Mew & Mew, Squeak, Moan, Meow, Trill-meow \\
Purr & - \\
Trill & Chirrup, Grunt, Trill-meow \\
Howel & Howl, Howl-growl \\
Growl & Growl, Howl-growl \\
Hiss & Hiss, Spit \\
Snarl & - \\
Chirp & Chirp, Chatter \\
\hline
\end{tabular}




\section{Onomatopoeia and Cat Vocalisations}

Most of the onomatopoeic words are neglected in dictionaries, although some languages have specific ones, like the English and Spanish Dictionary of onomatopoeic sounds, tones and noises in English and Spanish (Kloe, 1977). The data complication is taken from various studies and general dictionaries. The languages chosen for the current research were not randomly selected, as each language comes from a different family, in order to ensure the multiplicity of onomatopoeic words and yield adequate findings. Table 2 shows the onomatopoeic word for cat sounds in the various languages used in this study.

Table 2. Typology of onomatopoeic words for cat sounds in 10 languages

\begin{tabular}{llll}
\hline Language & Language Family & Cat Sound & Source \\
\hline English & Indo-European & $/ \mathrm{mi} \mathbf{\prime}^{\prime}$ ao/ & Jones, 2011 \\
Arabic & Afro-Asiati & $/$ muwaa/ & Abdul-Raof, 2000 \\
Indonesian & Austronesian & $/ \mathrm{meon} /$ & Tohari, Asmarandani \& Wijayadi, 2016 \\
Japanese & Japonic & $/$ nyä/ & Millington, 1993 \\
Chinese & Sino-Tibetan & $/ \mathrm{miao} /$ & Pollard \& Chan, 2001 \\
Korean & Koreanic & $/$ ya ong/ & Choo, 2008 \\
Turkish & Turkic & $/ \mathrm{miav} /$ & Walker, 1990 \\
Thai & Kra-Dai & $/ \mathrm{meeow} /$ & McFarlan, 1944 \\
Tagalog & Dravidian & $/ \mathrm{miyaw} /$ & Siddiq, 2019 \\
Hungarian & Uralic & $/ \mathrm{miau} /$ & Lesser, 2019 \\
\hline
\end{tabular}

Concerning the cat vocalisations, as mentioned in the background section, previous studies and analysis have identified the most common cat vocalisations based on recordings and developed a comprehensive phonetic typology, along with the phonetic descriptions shown in Table 1. It should be noted that only the meow types, along with the phonetic transcriptions demonstrated in Table 3, will be the focus of this study since most of the onomatopoeic words are indeed an imitation of this type.

Table 3. Classification of Meow Types (Schötz, Weijer, \& Eklund, 2017, p. 6)

\begin{tabular}{ll}
\hline Meow Types & Phonetic Transcriptions \\
\hline Mew & {$[\mathrm{mi}],[\mathrm{wI}]$ or $[\mathrm{mru}]$} \\
Squeak & {$[\mathrm{wæ}]$ or $[\mathrm{m} \varepsilon]$} \\
Moan & {$[\mathrm{moau}]$ or $[\mathrm{mæu}]$} \\
Meow & {$[\mathrm{miau}]$ or $[\mathrm{wav}]$ or $[\mathrm{\varepsilon au}]$} \\
\hline
\end{tabular}

Apparently, the two sets of data can be preliminarily used to analyse phonetically the cross-linguistic onomatopoeic cat sound in contrast to the phonetic structuring of natural cat vocalisations (Schötz, Weijer, \& Eklund, 2017). It can be clearly seen that most of the onomatopoeic words are indeed an imitation of the cat meow types presented in Table 3, which is the sound produced with an opening-closing mouth. The meow types include several subtypes: mew, squeak, moan and meow. The vowel quality of Mew is [i], [I] or [e], with a high-pitched, while Squeak with $[\varepsilon]$ vowel quality is nasal and high-pitched, besides the Moan and Meow types where Moan with [o] or [u] vowel quality and Meow with vowel pattern [iau] (Schötz, Weijer, \& Eklund, 2017). These natural cat vocalisations have often been observed in cat-human communication (Schötz, Weijer, \& Eklund, 2017). Remarkably, some languages - to be precise, English and Hungarian - have an identical combination of vowels in the characteristic [iau] similar to the cat vocalisations [miau]. By examining the two sets, two main phonological aspects are concerned, segmental and phonotactic variations. Concerning the segmental variations, the dataset indicates several consonant and vowel differences are particularly identified. Evidence from the dataset reveals that one striking regularity is that vowels are notably more frequent than consonants in both sets. In term of manner of articulation classes, nasal and approximant (glide) are the only classes in both sets with rarely attested classes such as fricative and plosive in the onomatopoeic words, as in the Turkish and Korean onomatopoeic words /miav/ and /yaong/, respectively. Concerning the consonants, only voiced consonants are identified where the nasal $[\mathrm{m}]$ and glide $[\mathrm{w}]$ are considered the most frequent segments in both sets, while $[\mathrm{g}, \mathrm{v}, \mathrm{y}]$ are less frequent consonants, found only in onomatopoeic words. Additionally, close vowels $[i, \mathrm{u}, \mathrm{o}]$ are considered the most frequent sounds in both sets. Phonotactically, eight syllable structure types have been identified in both sets, where the most frequent patterns are CV, CVV and CVVV. Another 
interesting finding of the dataset is that open syllables are the most preferred syllable structure, while clusters are rarely identified in both sets, only noticed in Korean onomatopoeia /yaong/. In sum, these are the main findings that the dataset revealing consonantal and phonotactic variations in onomatopoeic words, whereas cat vocalisations exhibit only vowel variations.

\section{Discussion}

When different languages attempt to imitate the same sound, they are restricted to using their own linguistic resources, leading to the fact that even the same natural sound ends up with a variety of forms in different languages. Generally speaking, the onomatopoeic words for cat sounds constitute the strongest evidence for non-arbitrariness, in which the meaning is clearly predictable from the form as seen in the study findings. Indeed, onomatopoeic cat sounds are extremely non-arbitrary, since the connections between the form and the meaning show a perfect example of iconicity as they are direct representations of their meanings due to natural derivation, cross-linguistically. In this research, regarding our first question, it can be concluded that the cross-linguistic onomatopoeic cat sounds were to some extent identical to cat vocalisations, showing some segmental and phonotactic differences in sounds and syllable structure. Nevertheless, the different phonological or morphological systems of every language considered in the study lead us to the fact that onomatopoeic cat sounds can surely be considered a perfect example of iconicity.

\section{Conclusion}

Cats communicate by making the same sounds, no matter in what country, but the way of representing their sounds might differ cross-linguistically. In this study, 10 onomatopoeic words for cat sounds in 10 languages, in contrast to cats' natural vocalisations, have been phonetically analysed. The findings revealed some segmental and phonotactical distinctions between onomatopoeia and natural cat vocalisations, due to the different phonological systems cross-linguistically. They provide strong evidence of the non-arbitrary aspect of onomatopoeic words for cat sounds cross-linguistically and show clearly their iconicity. To investigate other onomatopoeic words phonetically, more in-depth research is required, perhaps following the approach adopted in this study. In conclusion, it might be suggested to extend the research study on onomatopoeia and other animal vocalisations, to explore more widely the notion of iconicity and the arbitrariness of language cross-linguistically.

\section{Acknowledgments}

The author would like to thank the Research Center at Taibah University, for funding this research project.

\section{References}

Abdul-Raof, H. (2000). Arabic Stylistics: A Coursebook. Otto Harrassowitz Verlag.

Abelin, Å. (1999). Studies in Sound Symbolism. Göteborg: Department of Linguistics Göteborg University.

Chalker, S., \& Weiner, E. S. C. (1998). The Oxford Dictionary of English Grammar. Oxford University Press. https://doi.org/10.1093/acref/9780192800879.001.0001

Choo, M. (2008). Using Korean: A Guide to Contemporary Usage. Cambridge University Press. https://doi.org/10.1017/CBO9781139168496

Corballis, M. C. (1999). The Gestural Origins of Language. American Scientist, 87(2), 138. https://doi.org/10.1511/1999.2.138

de Saussure, F. (1959). Course in General Linguistics. New York: Philosophical Library.

Dofs. E. (2008). Onomatopoeia and Iconicity (A Comparative Study of English and Swedish Animal Sounds). MA Thesis, Karstads University.

Driscoll, C. A., Clutton-Brock, J., Kitchener, A. C., \& O’Brien, S. J. (2009). The Taming of the cat. Scientific American, 300(6), 68-75. https://doi.org/10.1038/scientificamerican0609-68

Gasser, M. (2006). Iconicity and arbitrariness in spoken words. Retrieved March 4, 2020, from http://www.indiana.edu/ hlw/PhonUnits/iconicity.html

Jones, D. (2011). Cambridge English Pronouncing Dictionary. Cambridge: Cambridge University Press.

Klages, M. (2001). Structuralism and Saussure. Retrieved June 5, 2020, from http://www.colorado.edu/English/courses/ENGL2012Klages/saussure.html

Lesser. J. D. (2019). English/Hungarian Dictionary. Joseph D. Lesser.

Matthews, P. H. (1997). The Concise Oxford Dictionary of Linguistics. Oxford University Press. 
McFarlan. G. B. (1944). Thai-English Dictionary. Stanford University Press.

McKinley, P. E. (1982). Cluster Analysis of the Domestic Cat's Vocal Repertoire. University of Maryland.

Millington, S. (1993). Nihongo Pera Pera: A User's Guide to Japanese Onomatopoeia. Charles E. Tuttle Company.

Moelk, M. (1944). Vocalizing in the House-Cat; A Phonetic and Functional Study. The American Journal of Psychology, 57(2), 184-205. https://doi.org/10.2307/1416947

Nicastro, N. (2004). Perceptual and Acoustic Evidence for Species-Level Differences in Meow Vocalizations by Domestic Cats (Felis catus) and African Wild Cats (Felis silvestris lybica). Journal of Comparative Psychology, 118(3), 287-296. https://doi.org/10.1037/0735-7036.118.3.287

Peirce, C. S. (1867), Upon Logical Comprehension and Extension. Proceedings of the American Academy of Arts and Sciences, 7, 416-432. https://doi.org/10.2307/20179572

Pollard, D. E., \& Chan, S. (2001). An Encyclopaedia of Translation: Chinese-English, English-Chinese. Chinese University Press.

Schötz, S. (2012). A phonetic pilot study of vocalisations in three cats (pp. 45-48). In Proceedings of Fonetik 2012, Department of Philosophy, Linguistics and Theory of Science, University of Gothenburg.

Schötz, S. (2013). A phonetic pilot study of chirp, chatter, tweet and tweedle in three domestic cats (pp. 65-68). In Proceedings of Fonetik 2013, Linköping University.

Schötz, S. (2015). Agonistic Vocalisations in Domestic Cats: A Case Study. Working Papers, 55, 85-90.

Schötz, S., \& Eklund, R. (2011). A Comparative Acoustic Analysis of Purring in Four Cats. In Proceedings of Fonetik 2011, Speech, Music and Hearing, KTH, Stockholm, TMH-QPSR.

Schötz, S., Weijer, J., \& Eklund, R. (2017). Phonetic Characteristics of Domestic Cat Vocalisations. Preceedings of the 1st International Workshop on Vocal Interactivity in-and-between Humans. Animals and Robots, VIHAR 2017 At: 25-26 August 2017, University of Skövde, Sweden.

Siddiq, M. B. (2019). Onomatopoeia and Word Class Categories Analysis in Hulk Digital Comic. Proceedings of the 2nd English Education International Conference (EEIC) in conjunction with the 9th Annual International Conference (AIC), Uniersitas Syiah Kuala, September 18-19.

Tohari, C. A., Asmarandani, A. I., \& Wijayadi. (2016). The Phonological Analysis of Animal Sounds in English and Indonesians. Tell Journal, 4(1).

Turner, D. C., \& Bateson, P. P. G. (2000). The domestic cat: The biology of its behaviour (2nd ed.). New York: Cambridge University Press.

Valli, \& Lucas. (2000). Linguistics of American Sign Language: An Introduction. Gallaudet University Press.

Walker, B. K. (1990). The Art of the Turkish Tale (vol. 1). Texas Tech University Press,

Yaqubi, M., Tahir, R. I., \& Amini, M. (2018). Translation of Onomatopoeia: Somewhere between Equivalence and Function. Studies in Linguistics and Literature, 2(3), 205. https://doi.org/10.22158/sll.v2n3p205

\section{Copyrights}

Copyright for this article is retained by the author, with first publication rights granted to the journal.

This is an open-access article distributed under the terms and conditions of the Creative Commons Attribution license (http://creativecommons.org/licenses/by/4.0/). 